\title{
A synthesis of the effect of grazing exclusion on carbon dynamics in grasslands in China
}

\author{
ZHONGMIN HU ${ }^{1}$, SHENGGONG LI ${ }^{1}$, QUN GUO $^{1}$, SHULI NIU ${ }^{1}$, NIANPENG HE ${ }^{1}$, \\ LINGHAO LI ${ }^{2}$ and GUIRUI YU ${ }^{1}$ \\ ${ }^{1}$ Synthesis Research Center of Chinese Ecosystem Research Network, Key Laboratory of Ecosystem Network Observation and \\ Modeling, Institute of Geographic Sciences and Natural Resources Research, Chinese Academy of Sciences, Beijing 100101, China, \\ ${ }^{2}$ Laboratory of Quantitative Vegetation Ecology, Institute of Botany, Chinese Academy of Sciences, Beijing 100093, China
}

\begin{abstract}
Grazing exclusion (GE) is considered to be an effective approach to restore degraded grasslands and to improve their carbon $(\mathrm{C})$ sequestration. However, the $\mathrm{C}$ dynamics and related controlling factors in grasslands with GE have not been well characterized. This synthesis examines the dynamics of soil $\mathrm{C}$ content and vegetation biomass with the recovery age through synthesizing results of 51 sites in grasslands in China. The results illustrate increases in soil $\mathrm{C}$ content and vegetation biomass with GE at most sites. Generally, both soil C content and vegetation biomass arrive at steady state after 15 years of GE. In comparison, the rates of increase in above- and belowground biomass declined exponentially with the age of GE, whereas soil C content declined in a milder (linear) way, implying a lagged response of soil $\mathrm{C}$ to the inputs from plant biomass. Mean annual precipitation (MAP) and the rate of soil nitrogen (N) change were the main factors affecting the rate of soil $\mathrm{C}$ content change. MAP played a major role at the early stage, whereas the rate of soil $\mathrm{N}$ change was the major contributor at the middle and late stages. Our results imply that the national grassland restoration projects in China may be more beneficial for $\mathrm{C}$ sequestration in humid regions with high MAP. In addition, increased soil $\mathrm{N}$ supply to grasslands with GE at the latter recovery stage may enhance ecosystem $\mathrm{C}$ sequestration capacity.
\end{abstract}

Keywords: biomass, C dynamics, grassland, grazing exclusion, soil carbon, soil nitrogen, steady state

Received 1 May 2015 and accepted 9 October 2015

\section{Introduction}

Covering ca. $40 \%$ of the earth's land surface, grasslands can serve as a source of feedback for global climate through their strong potential for carbon sequestration (Wang \& Fang, 2009). Grazing is a key factor affecting soil C storage in grasslands (Mcsherry \& Ritchie, 2013). Globally, overgrazing is one of the most important human disturbances, causing severe degradation of grasslands (Su et al., 2005; Liang et al., 2009) and reducing both productivity and resilience of grasslands (Zhou et al., 2011). Grazing exclusion (GE) is considered to be an effective approach to restore degraded grassland ecosystems, as well as to promote $\mathrm{C}$ sequestration (Akiyama \& Kawamura, 2007; He et al., 2009; Souter \& Milne, 2009; Wu et al., 2010; Qiu et al., 2013).

Soil and vegetation biomass are the major $C$ pools in the ecosystem. Despite the importance of GE in grassland carbon sequestration, the dynamics of $\mathrm{C}$ pools and related controlling factors as a result of GE are not well characterized. For example, no general conclusion on

Correspondence: Dr Guirui Yu, tel. 8610-64889438, fax +8610 64889438, e-mail: yugr@igsnrr.ac.cn whether GE promotes or reduces soil carbon has been drawn yet. Although many studies document increased soil C accumulation with GE (Hiernaux et al., 1999; Su et al., 2005; Mekuria et al., 2007; Pei et al., 2008; Steffens et al., 2008), some report negligible or decreased changes in soil C (Reeder \& Schuman, 2002; Derner et al., 2006; Nosetto et al., 2006; Shrestha \& Stahl, 2008). Due to this lack of consensus on the effect of GE on soil $\mathrm{C}$, there is little knowledge about how much $\mathrm{C}$ is sequestrated (or lost) per year for grasslands with GE. In addition, most individual studies focus merely on comparison of ecosystem $\mathrm{C}$ between the GE plots and the grazing plots. Therefore, little is known about the trajectory of ecosystem $\mathrm{C}$ dynamics along the age gradient and the differences among sites with different climatic conditions. Specifically, we know little about how many years the grassland $C$ pools require to recover to the steady (or equilibrium) state, and how the rates of changes in $\mathrm{C}$ pools differ across sites in relation to environmental conditions (Mcsherry \& Ritchie, 2013).

Grasslands in China cover approximately $40 \%$ of the total national land, accounting for approximately 9$16 \%$ of the world's grassland carbon stocks (Fan et al., 2008). The Chinese government has invested heavily to 
restore degraded grasslands in the past 20 years. For example, the 'Start-up Re-grass Program' was implemented to protect grasslands through GE from heavy grazing pressures (Jiang et al., 2006). Investigating the dynamics of $\mathrm{C}$ pools as a result of GE has significant regional and global implications in terms of ecosystem management.

Through compilation and analysis of published data from individual studies on grasslands in China, this study aims to examine the dynamics of $\mathrm{C}$ pools (i.e., soil and plant biomass) during the ecosystem recovery process following GE. The objective of this study is to address the following questions: (i) How much $\mathrm{C}$ can be sequestrated (or lost) per year in C pools for grasslands in China with GE? (ii) What are the different trajectories of the rates of changes in $\mathrm{C}$ pools along the age of GE? After how many years does the ecosystem recover to a steady state? (iii) How does the rate of $\mathrm{C}$ change vary across sites and how does it relate with climatic factors? We hypothesize that GE improves both vegetation biomass and $C$ content in soil, and that the rates of increase for all $\mathrm{C}$ pools decline linearly with age. As soil plays a predominant role for carbon storage in grassland ecosystems, our analysis mainly focuses on soil C content.

\section{Materials and methods}

\section{Data compilation}

A database was compiled by searching the Web of Science and China National Knowledge Infrastructure for studies that were published before April 2014. The following key words were used to select the studies: GE, fencing, soil carbon/nitrogen content/stock, biomass, grassland, China/Chinese. Only studies using paired-site chronosequence, with similar soil and climatic conditions for both the grazing and nongrazing sites, were selected for the database. In cases with more than one data set published at the same site but in different reports, the report with the longest record was chosen or the data sets were integrated into the longest record. In cases where not soil C content but soil organic matter was measured, a correcting factor of 0.58 was used to convert organic matter into soil C content (Poeplau et al., 2011). In studies with soil C stock and soil bulk density reported, soil C content was calculated according to the profile data of soil bulk density. In total, the data set included 51 sites reported by 50 peer-reviewed papers (Fig. 1, Table S1).

The raw data were either obtained from tables or extracted by digitizing graphs using the GetData Graph Digitizer (version 2.24, Russian Federation). For each paper selected, the following information was compiled: location (longitude and latitude), climatic information [mean annual temperature (MAT) and mean annual precipitation (MAP)], years of GE, sampling depth, soil classification, soil bulk density, amount of soil $\mathrm{C}$ and $\mathrm{N}$, aboveground biomass (AGB), belowground biomass (BGB). To depict more apparent trends of the $C$ pools, the ages of GE were divided into ten groups: 1-3, 4-6, 7-9, 10$12,13-15,16-18,19-21,22-24,25-27$, and $>27$ years.

\section{Data calculation and analysis}

All studies included measurements of changes in C pools during at least one time interval. This allowed to calculate the rate of absolute change by dividing the total $\mathrm{C}$ change by the time since GE (Yang et al., 2011; Li et al., 2012):

$$
\text { Rate of change }=\frac{\Delta X}{\Delta t}
$$

where $\Delta X$ denotes the change of $C$ (or $N$, or biomass) since $\mathrm{GE}$, and $\Delta t$ represents time of GE (year). For example, if the soil $\mathrm{C}$ content in a 10 -year fenced plot is $50 \mathrm{~g} \mathrm{~kg}^{-1}$, and that in the nearby free grazed plot is $40 \mathrm{~g} \mathrm{~kg}^{-1}$, the rate of change is: $(50-40) \div 10=1 \mathrm{~g} \mathrm{~kg}^{-1} \mathrm{yr}^{-1}$.

Sampling depths for BGB varied in different studies. Considering that most root biomass is distributed in the first $30 \mathrm{~cm}$ and most studies sampled root to this depth, data of root biomass in $0-30 \mathrm{~cm}$ were used to investigate the rate of change in BGB.

Mean rates of changes in soil $\mathrm{C}$ content and vegetation biomass for all measurements were calculated with 95\% confidence intervals (CI). 95\% CI was calculated as 1.96 times of standard error (SE). T-tests were conducted to evaluate whether GE significantly increased C pools. ANOvA was conducted to evaluate whether the rates of changes in soil C content and vegetation biomass were significantly different among different recovery ages. Regression analysis was conducted to analyze the relationships between the rates of soil $\mathrm{C}$ change and climatic factors, and the rates of soil $\mathrm{N}$ change. In addition, a general linear model (GLM) analysis was conducted to quantify the contributions of relevant factors to the variations in the rates of soil $\mathrm{C}$ change.

\section{Results}

\section{Changes in soil carbon content}

The rates of soil C content change varied greatly among observations, exhibiting a skewed distribution (Fig. 2). Briefly, 299 of the total 326 measurements (i.e., 92\%) illustrated increases of soil C content with GE. The mean rate of soil $\mathrm{C}$ change was $0.37(95 \% \mathrm{CI}=0.06)$ $\mathrm{g} \mathrm{kg}^{-1} \mathrm{yr}^{-1}$. This result indicates that soil $\mathrm{C}$ content increased with GE at most sites in grasslands in China. The increase of soil $\mathrm{C}$ content was in most cases less than $1 \mathrm{~g} \mathrm{~kg}^{-1} \mathrm{yr}^{-1}$, but could be as large as more than $3 \mathrm{~g} \mathrm{~kg}^{-1} \mathrm{yr}^{-1}$ in seldom cases (Fig. 2).

According to the differences in magnitude of the increase of soil $\mathrm{C}$, three periods can be determined: 1-3 years, $4-15$ years, and $>15$ years (Fig. 3a). The rates of change in soil $\mathrm{C}$ content were significantly different among the three periods (ANOvA, $P<0.05$ ), with 


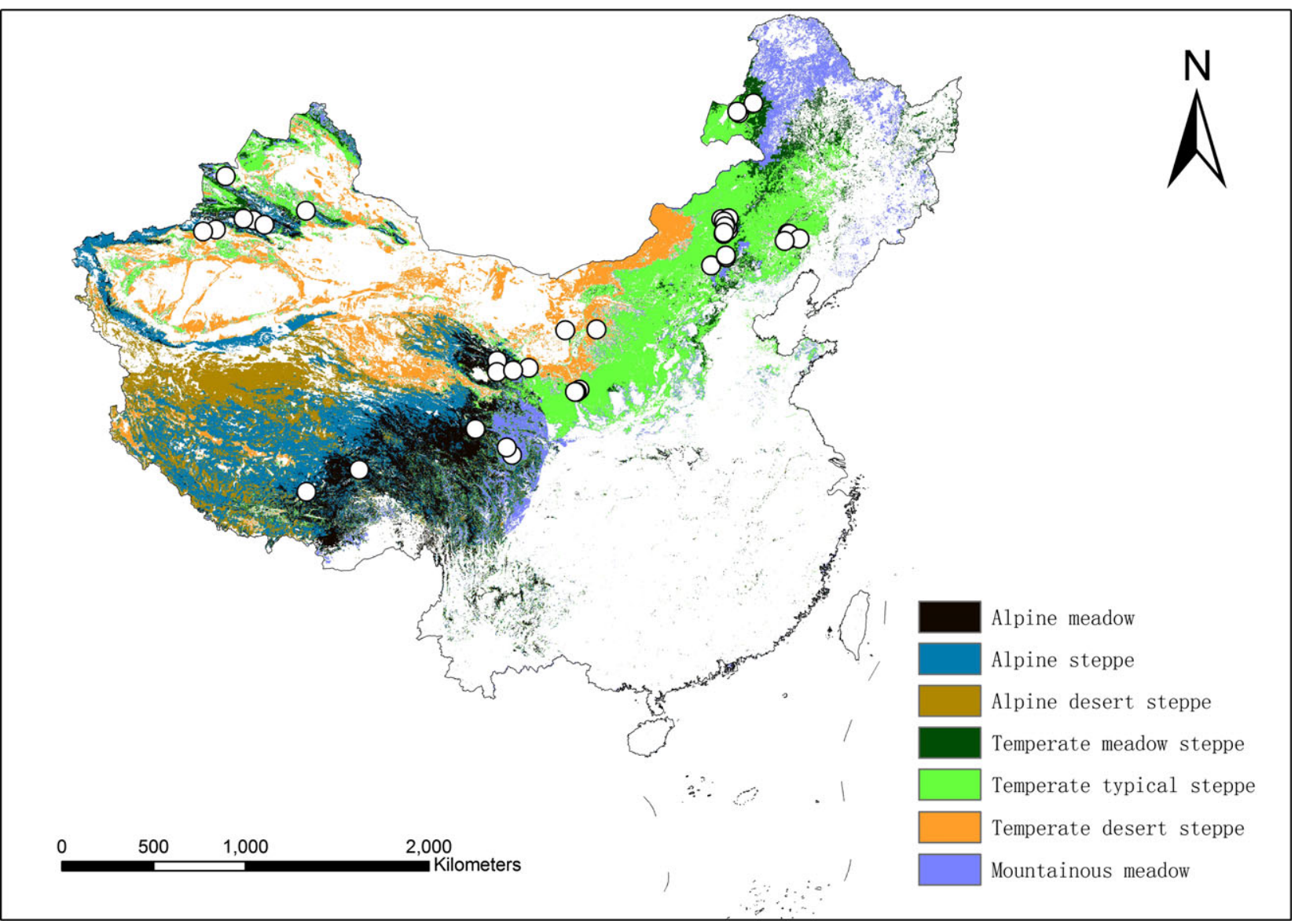

Fig. 1 Locations of the individual studies included in this synthesis.

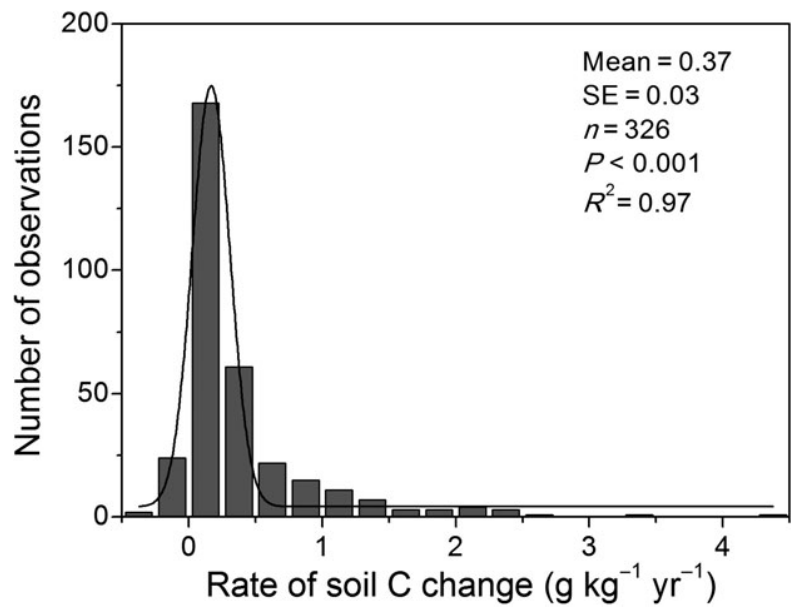

Fig. 2 Frequency distribution of the rate of soil C content change with grazing exclusion. The curve was fitted by a Gaussian function.

substantial increases in the first period $\left(1.01 \mathrm{~g} \mathrm{~kg}^{-1} \mathrm{yr}^{-1}\right)$, mild increases in the second period $\left(0.50 \mathrm{~g} \mathrm{~kg}^{-1} \mathrm{yr}^{-1}\right)$, and subtle increases in the third period $\left(0.15 \mathrm{~g} \mathrm{~kg}^{-1} \mathrm{yr}^{-1}\right)$. In addition, great spatial variability was found in the first period with a SE of $0.27 \mathrm{~g} \mathrm{~kg}^{-1} \mathrm{yr}^{-1}$, with reductions of soil $\mathrm{C}$ being observed at some sites. Consistent increase of soil C was observed at most sites in the latter two periods, however, with SE less than $0.1 \mathrm{~g} \mathrm{~kg}^{-1} \mathrm{yr}^{-1}$.

Grazing exclusion improves soil $\mathrm{C}$ content as deep as more than $50 \mathrm{~cm}$. Despite a considerable variability among individual measurements, the magnitude of change was the largest in the surface layer and declined with soil depth for soil above $50 \mathrm{~cm}$ (Fig. 3b). The average rate of increase was $0.55 \mathrm{~g} \mathrm{~kg}^{-1} \mathrm{yr}^{-1}$ in $0-10 \mathrm{~cm}$, followed by $0.38 \mathrm{~g} \mathrm{~kg}^{-1} \mathrm{yr}^{-1}$ in $10-20 \mathrm{~cm}$, $0.29 \mathrm{~g} \mathrm{~kg}^{-1} \mathrm{yr}^{-1}$ in $20-30 \mathrm{~cm}$, and $0.14 \mathrm{~g} \mathrm{~kg}^{-1} \mathrm{yr}^{-1}$ in $30-50 \mathrm{~cm}$. A notable higher increase rate of soil C, although not significant, was found in the layer of $>50 \mathrm{~cm}$ (and $<100 \mathrm{~cm}, 0.22 \mathrm{~g} \mathrm{~kg}^{-1} \mathrm{yr}^{-1}$ ) compared with the shallower layer between 30 and $50 \mathrm{~cm}$.

\section{Changes in vegetation biomass}

Grazing exclusion promoted both above- and BGB with the magnitude of increase rate declining for longer durations of GE (Fig. 4). On average, the rate of AGB 


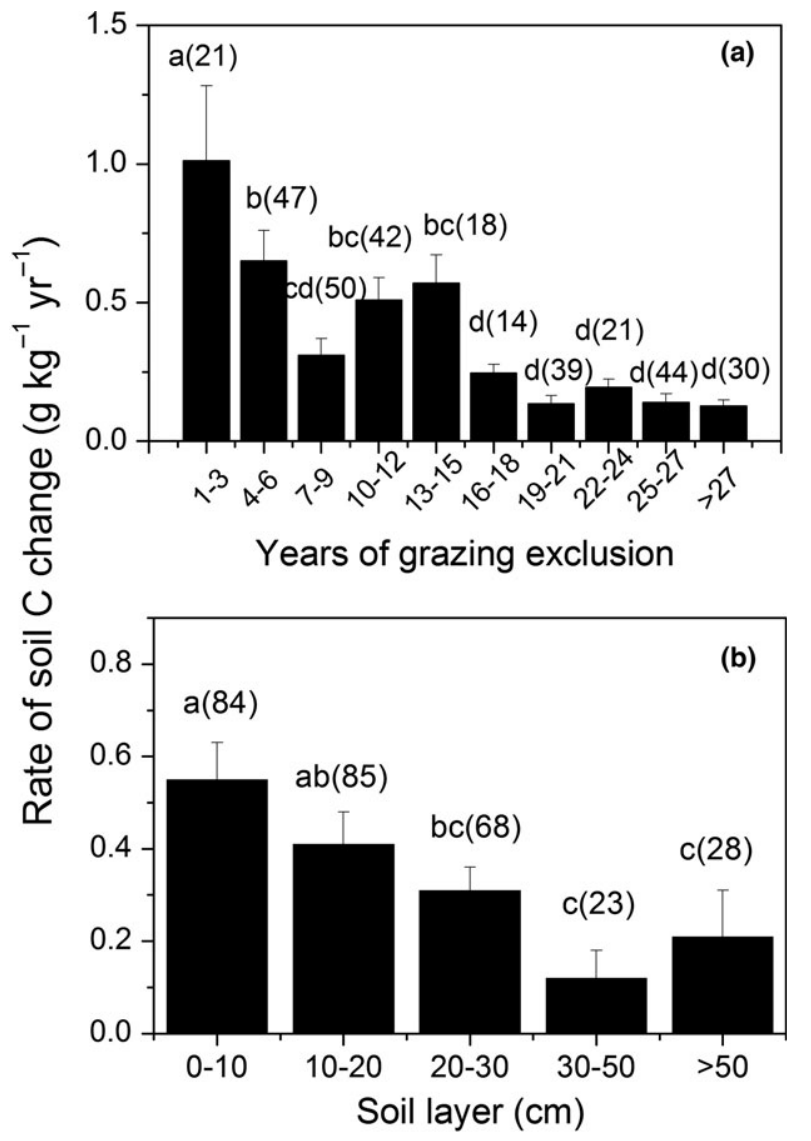

Fig. 3 Variations of the rate of soil $\mathrm{C}$ change with the ages of grazing exclusion (a), and at different soil layers (b). The error bars illustrate one-standard errors. The same letters indicate nonsignificant difference at 0.05 level. Values in parenthesis are the number of measurements.

change was $21.1 \mathrm{~g} \mathrm{~m}^{-2} \mathrm{yr}^{-1}$ (95\% CI = 6.1). Similar to the temporal dynamics of the rate of soil $\mathrm{C}$ content change, the same three distinct stages were detected for the rate of AGB change, i.e., 1-3, 4-15, and $>15$ years (ANOVA, $P<0.05$ ). The increase of AGB was most obvious $\left(49.5 \mathrm{~g} \mathrm{~m}^{-2} \mathrm{yr}^{-1}\right)$ in the first stage, mild $\left(20.6 \mathrm{~g} \mathrm{~m}^{-2} \mathrm{yr}^{-1}\right)$ in the second stage, and minor $\left(5.2 \mathrm{~g} \mathrm{~m}^{-2} \mathrm{yr}^{-1}\right)$ in the third stage (Fig. 4a). On average, GE increased BGB by $2.23 \mathrm{~g} \mathrm{~cm}^{-1} \mathrm{yr}^{-1}(95 \%$ $C I=0.86)$, with three distinct stages also for the rate of BGB change (ANOvA, $P<0.05$, Fig. $4 \mathrm{~b}$ ). However, the duration of large increase (i.e., the first stage) of BGB was longer than for AGB and soil C content. An obvious increase of BGB was found in the first 6 years (3.69 $\left.\mathrm{g} \mathrm{cm}^{-1} \mathrm{yr}^{-1}\right)$, followed by mild increase in years $7-15\left(1.35 \mathrm{~g} \mathrm{~cm}^{-1} \mathrm{yr}^{-1}\right)$, and minor increase in years $>15\left(0.49 \mathrm{~g} \mathrm{~cm}^{-1} \mathrm{yr}^{-1}\right)$.

Regressing the rates of changes in $C$ pools with the age of GE, yielded an exponential decrease depicting the dynamics of the rates of changes in AGB and
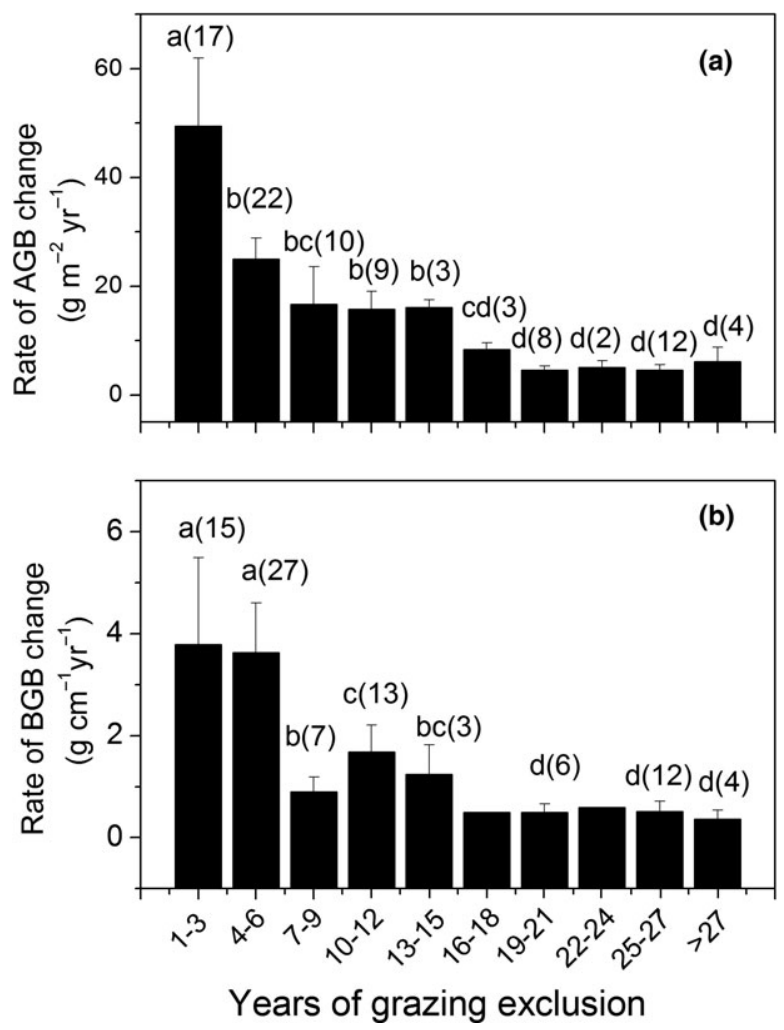

Fig. 4 Variations of the rates of changes in aboveground biomass, AGB (a), and belowground biomass, BGB (b), with the age of grazing exclusion.

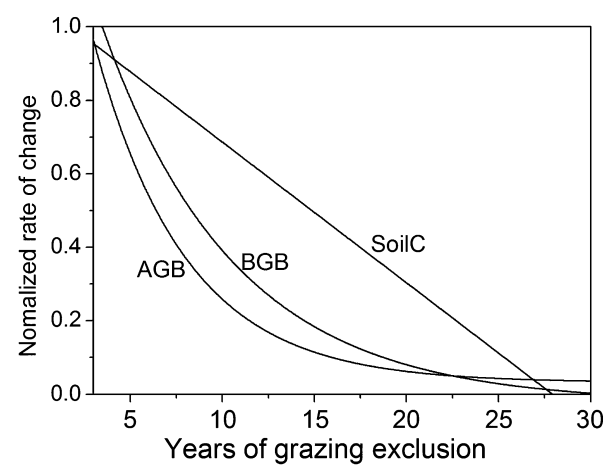

Fig. 5 Conceptual dynamics of the rate of changes in ecosystem carbon pools with the age of grazing exclusion. AGB, aboveground biomass; BGB, belowground biomass; SoilC, soil carbon content. The rates of change were normalized to the range of 0 and 1.

BGB and a linear decrease depicting the dynamics of the rate of soil $\mathrm{C}$ content change (Fig. 5). In comparison, AGB reached a steady state (i.e., the rate of change became marginal) first, followed by BGB, and soil $\mathrm{C}$ content, indicating that the increase of soil $\mathrm{C}$ content lags behind the accumulation of vegetation biomass. 


\section{Effects of climate and nitrogen on soil carbon sequestration}

Geographically, the rate of soil C change (average of 0-30 $\mathrm{cm}$ ) illustrated a significant decrease trend with longitude $\left(R^{2}=0.41, \quad P<0.01\right)$, but no significant trend with latitude $(P>0.05)$ (Fig. 6). Among the two climatic factors, i.e., MAT and MAP, only for MAP a significant correlation with the rate of soil $\mathrm{C}$ change $(P<0.05)$, which can explain $37 \%$ of the variability among observations, was found. This indicates that precipitation is the main climatic factor determining the intersite differences of the rates of soil $\mathrm{C}$ change as a result of GE. Alpine grassland and temperate grassland are the major grassland types in China. Most alpine grassland ecosystems in our synthesis are located in the west of 100 degrees in longitude and the climate is wetter than in the temperate steppe. This implies that alpine grassland has a higher potential for $C$ sequestration as a result of GE compared with temperate grassland.

A significant correlation between the rates of soil C content change and the rates of soil $\mathrm{N}$ content change was found in grasslands with GE, indicating that soil $\mathrm{C}$ content change is strongly coupled with $\mathrm{N}$ content change $\left(P<0.01\right.$, Fig. 7a). On average, $1 \mathrm{~g} \mathrm{~kg}^{-1}$ increase in $\mathrm{N}$ content was accompanied by $13.6 \mathrm{~g} \mathrm{~kg}^{-1}$ increase in $\mathrm{C}$ content. It should be noted that the rate of soil C change increased exponentially with that of soil $\mathrm{N}$, implying that the 'nitrogen-use efficiency' declined with the age of GE. Soil C content and soil $\mathrm{N}$ content were linearly correlated $(P<0.01)$, with a slope of 11.1 and 11.6 at grazing and GE sites, respectively (data not shown). The two slopes were not significantly different at 0.05 level, indicating that soil $\mathrm{C}: \mathrm{N}$ ratio is generally stable during the whole process of recovery. However, soil $\mathrm{C}: \mathrm{N}$ ratios at GE sites were significantly higher compared with grazing sites in the late recovery stage (i.e., $>15$ years). This indicates that the supply of $\mathrm{N}$ could not keep up with the pace of soil $\mathrm{C}$ increase in the late stage (Fig. 7b).

These findings illustrate the important roles of MAP and the rate of soil $\mathrm{N}$ change in affecting the spatial variability of the rate of soil $\mathrm{C}$ change. Further GLM analysis indicates that the contributions of the two factors vary at different recovery stages (Table 1$)$. At the early stage ( $<6$ year), MAP was the major contributor, explaining $54 \%$ of the variations in the rate of soil $\mathrm{C}$ change, whereas the rate of soil $\mathrm{N}$ change showed nonsignificant effect $(P>0.05)$. At the middle and late stages, however, the rate of soil $\mathrm{N}$ change contributed more than MAP. Overall, the rate of soil $\mathrm{N}$ change contributed $40 \%$, and MAP contributed $24 \%$ to the variations in the rates soil C change.
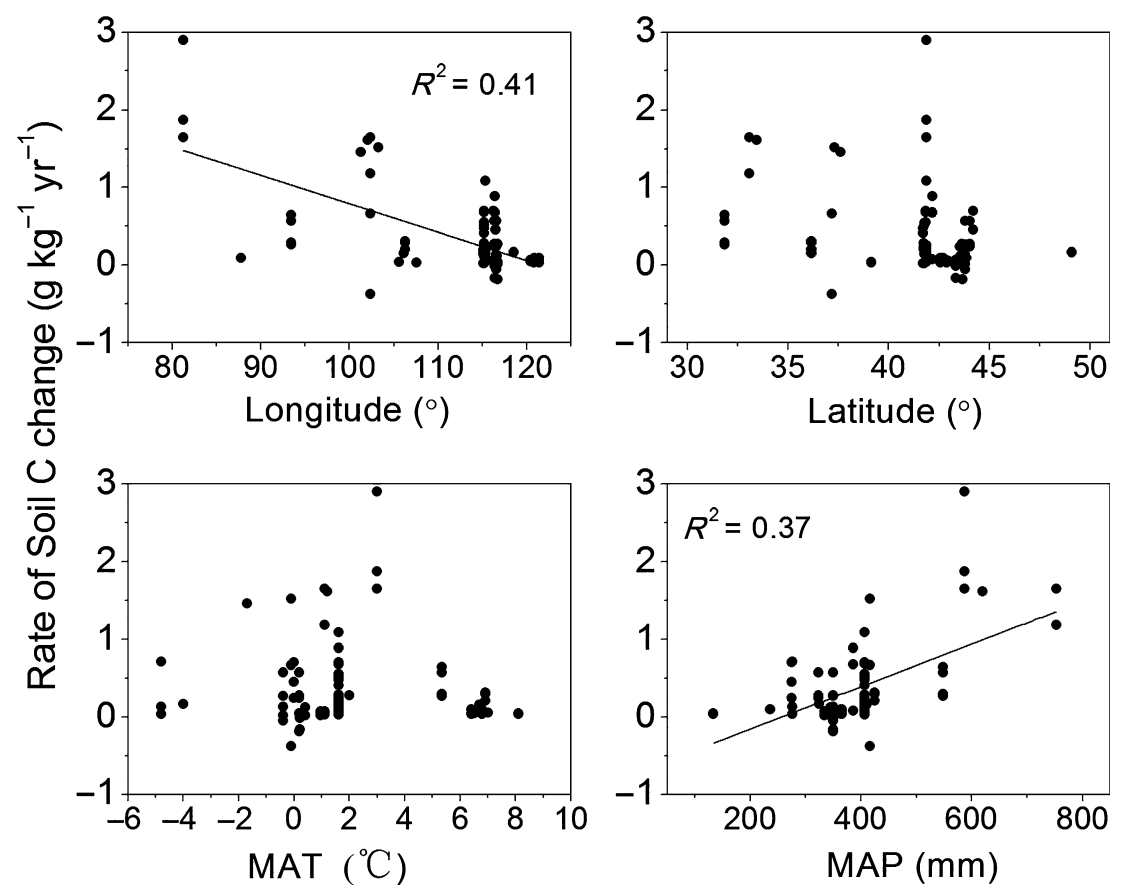

Fig. 6 Relationships between the rate of soil C change with geographic factors (longitude and latitude) and climatic factors (mean annual temperature and precipitation, i.e., MAT and MAP). 

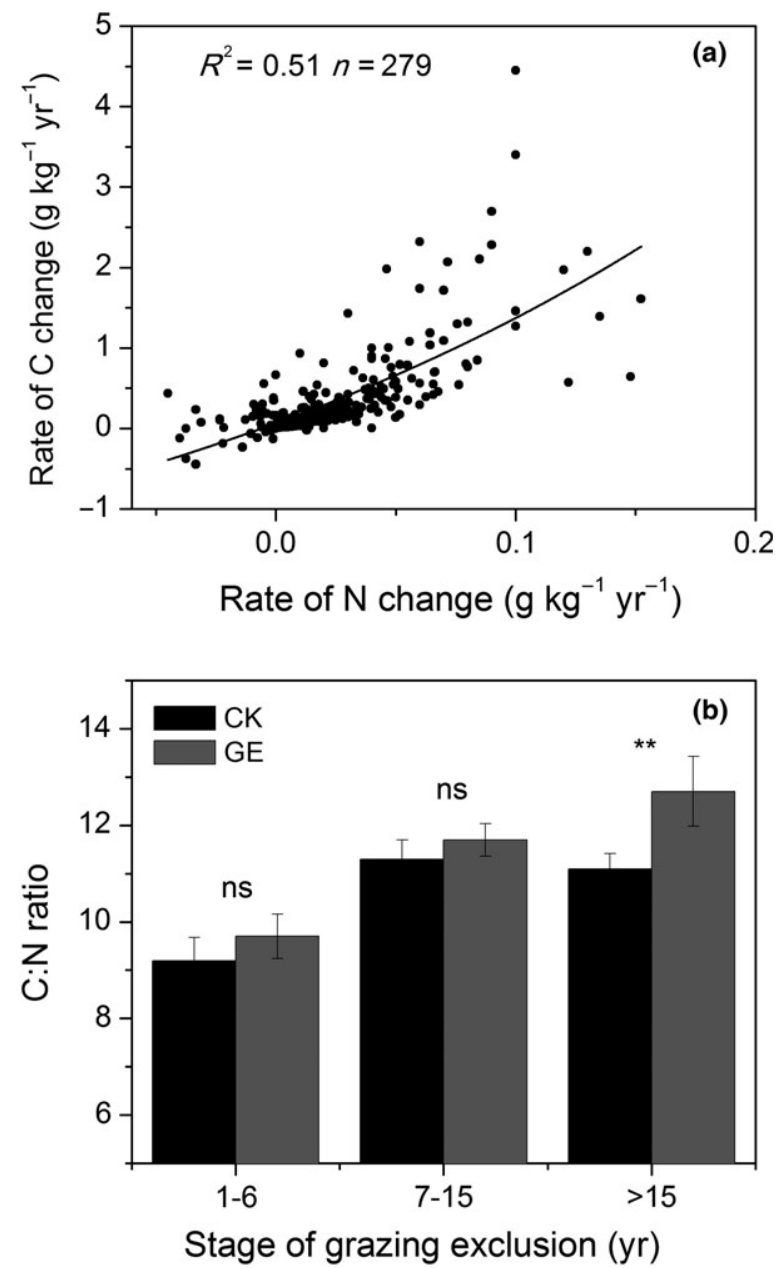

Fig. 7 Effect of grazing exclusion on carbon-nitrogen coupling relationship. (a) correlations between rates of soil $\mathrm{C}$ content change and rates of soil $\mathrm{N}$ content change. (b) Soil $\mathrm{C}: \mathrm{N}$ ratio at early ( $1-6$ years), middle ( $7-15$ years), and late ( $>15$ years) stages at grazing sites (CK) and grazing exclusion sites (GE). ns: nonsignificant difference. ${ }^{* *}$ : significant difference at 0.01 level.

Table 1 Contributions of MAP and $N_{\text {rate }}$ to the rate of soil C change at different stages of grazing exclusion

\begin{tabular}{llcl}
\hline Year & MAP $(\mathrm{ss} \%)$ & $N_{\text {rate }}(\mathrm{ss} \%)$ & Residual $(\mathrm{ss} \%)$ \\
\hline$<6$ & 54 & 1 & 45 \\
$6-15$ & 37 & 45 & 17 \\
$>15$ & 26 & 35 & 32 \\
Total & 24 & 40 & 36 \\
\hline
\end{tabular}

MAP, mean annual precipitation; $N_{\text {rate, }}$ rate of soil nitrogen change.

\section{Discussion}

Changes in soil carbon content as a result of GE

Obvious increases of soil $\mathrm{C}$ content as a result of GE were found at most sites (Fig. 2). This result is consistent with most studies on grasslands of the world (Hiernaux et al., 1999; Su et al., 2005; Mekuria et al., 2007; Pei et al., 2008; Steffens et al., 2008). Three mechanisms support this increase of soil C content. First, as a result of two processes, more organic matter accumulates in soil through vegetation recovery (Deng et al., 2014): (i) Excluding grazing reduces the output of carbon from the ecosystem to livestock; (ii) The increase of net primary productivity due to the removal of grazing pressure accelerates organic matter (litter, dead roots, mycorrhizae, and exudates) input into the soil. Second, the amelioration of soil moisture triggers a positive feedback resulting in higher plant productivity and C input (Wu et al., 2010). GE can increase soil moisture through improving the capacity of soil water conservation as a result of amelioration of soil texture and by reducing bare soil water evaporation due to the increase of vegetation height, canopy cover, and mulch (Savadogo et al., 2007; Pineiro et al., 2010). Third, vegetation recovery reduces $\mathrm{C}$ losses from wind erosion due to the denser plant canopy and higher mulch cover (Liu et al., 2003; Zhou et al., 2011). The rates of wind erosion in lightly degraded grasslands can be $>50 \%$ lower than for heavily degraded grasslands in Inner Mongolia (Hu et al., 2005).

For a few sites, nonsignificant change or even decrease of soil $C$ has been observed as a result of GE, particularly in the first 3 years (Fig. 3a). Similar results have also been reported for grasslands in other regions of the world (Wienhold et al., 2001; Reeder \& Schuman, 2002). Reasons for the decrease may be historical grazing practices and grazing intensities before GE (Shrestha \& Stahl, 2008). For example, short-grass prairie in the Great Plains of North America tended to increase soil organic C by $24 \%$ in plots under light and moderate grazing compared to plots without grazing (Derner et al., 2006). As there are insufficient data on grazing intensity over time for most sites in our synthesis, the influence of historical grazing practices on soil $\mathrm{C}$ dynamics during the period of GE could not be elaborated.

Based on the significant increase in soil C content, this synthesis supports the view that GE is an effective approach to promote ecosystem $\mathrm{C}$ sequestration for grasslands in China. Soil bulk density, another important factor determining soil C stock, however, was found to decrease as a result of GE (data not shown, Table S1). Intuitively, a decrease of soil bulk density owing to elimination of trampling by livestock and increase of soil porosity as the results of GE can be imagined. Actually, no change in total soil C stock occurs in this case as the decrease in soil bulk density is accompanied by an increase in 'soil depth'. Thus, a method of equivalent soil mass (ESM) is proposed to 
correct the underestimation of soil C stock resulting from the traditional 'fixed depth' method (Poeplau et al., 2011). In addition, some case studies also illustrate that, even without the ESM correction, soil C stock was found to increase as well, despite the decrease of soil bulk density in the temperate grassland in China with GE (He et al., 2008).

\section{Dynamics of ecosystem carbon pools}

Rates of changes in soil $\mathrm{C}$ content and plant biomass decline markedly with the age of GE. C pools tend to reach equilibrium at the late stage, indicating that age plays a major role in shaping the trajectory of $C$ dynamics. This result is consistent with the 'dynamic disequilibrium' theory, which states that disturbance leads to temporal changes in ecosystem $C$ pools within a short episode, but does not affect long-term C dynamics (Luo \& Weng, 2011). This synthesis also exhibits distinct trajectories for the $\mathrm{C}$ pools, with exponential decays of the rate of changes for above- and BGB, but a milder linear decay for that of soil C content (Fig. 5). These results are consistent with the expectation that changes in soil $\mathrm{C}$ content lag behind changes in vegetation biomass, as the latter is the major input of soil C.

Despite the distinct trajectories (i.e., exponential decay and linear decay), all the $C$ pools reach equilibrium after ca. 15 years of GE (Figs 3 and 4). To our knowledge, this is the first study that simultaneously quantifies the dynamics and the duration for $\mathrm{C}$ pools to reach steady state for grasslands with GE. The findings of this study have valuable implications for carbon sequestration through grassland. For example, with information on the duration and dynamics of $C$ sequestration before reaching the steady state, the carbon sequestration potential for grassland ecosystems can be evaluated.

\section{Effects of climatic factors on carbon sequestration}

This study illustrates that precipitation is the dominant climatic factors affecting the spatial variations of rate of soil C change. This indicates that GE can sequestrate more carbon under wetter climatic conditions. It is well established that both plant productivity (Luyssaert et al., 2007) and microbial activity (Raich \& Schlesinger, 1992) tend to be faster and higher under wetter than under drier conditions. Thus, the similar effects of climatic factors on $C$ inputs and outputs to soil could lead to weak correlations between the rate of soil $\mathrm{C}$ changes and climatic variables. However, the findings of this study imply that with the increase of MAP, the enhancement of plant photosynthesis is greater than ecosystem respiration, which dominants the $\mathrm{C}$ balance for the ecosystems in grasslands in China. These results are supported by the report of Xia et al. (2009), in which a control experiment in a temperate grassland in Inner Mongolia was conducted. This experiment showed that net ecosystem productivity was higher in wetter than in drier years, a key reason of which was the higher soil moisture sensitivity for photosynthesis than for ecosystem respiration. The findings of the current study also imply that GE might be more effective in regions with wetter climate.

In addition to climatic factors, soil texture is another key factor of the grazer effects on grassland soil C content (Mcsherry \& Ritchie, 2013). It is thus expected that soil texture also plays an important role in the process of recovery. Unfortunately, most studies included in our analysis do not provide quantified information on soil texture (mostly including only a general soil type description), which prevents further investigation on the effect of soil texture.

\section{Effects of soil $N$ on $C$ sequestration}

According to our synthesis, GE is an effective approach to improve $\mathrm{C}$ sequestration in grasslands in China. However, whether $C$ sequestration can be sustained is largely determined by the availability of $\mathrm{N}$, as additional $\mathrm{N}$ is required to support terrestrial $\mathrm{C}$ accumulation as a result of stoichiometric relationships in both vegetation and soil (Hungate et al., 2003; Luo et al., 2004). This study demonstrates a strong correlation between the changes of soil $\mathrm{C}$ and $\mathrm{N}$ content, indicating that soil $\mathrm{C}$ dynamics are closely coupled with $\mathrm{N}$ dynamics (Fig. 7). The increase of soil $\mathrm{N}$ will reduce $\mathrm{N}$ limitation and might be an important mechanism of the continuous $\mathrm{C}$ sequestration during the period of GE.

The increase of $\mathrm{N}$ may be the results of increase of $\mathrm{N}$ input, decrease of $\mathrm{N}$ loss, or both. GE can affect both the $\mathrm{N}$ inputs and outputs through three paths. First, the removal of grazing can return a part of $\mathrm{N}$ from livestock, which increases the $\mathrm{N}$ availability. As the direct effects of grazing pressure elimination can only sustain for limited years, it is likely that this mechanism is negligible in the middle and late stages. Second, the loss of $\mathrm{N}$ through wind erosion, leaching, as well as nitrification and denitrification processes might be alleviated as the vegetation recovers. It is reported that the wind erosion in fenced grasslands was much less than in grazed grasslands (Hu et al., 2005), implying a reduction in $\mathrm{N}$ loss through wind erosion. Also, with the amelioration of soil water content, gashouse $\mathrm{N}$ loss (e.g., $\mathrm{NO}, \mathrm{N}_{2} \mathrm{O}$, and $\mathrm{N}_{2}$ ) may decrease as a result of changes in nitrification and denitrification processes. A recent study of northern China temperate grasslands indicates that, under wetter climate, loss of $\mathrm{N}$ in gaseous forms due to 
denitrification declines and more $\mathrm{N}$ is absorbed by plants (Wang et al., 2014). Third, changes in plant composition with the development of vegetation also affect the input of N. Owing to their palatability, legume species are highly depressed under grazing conditions. The proportion of these species increases with the use of fencing, and more $\mathrm{N}$ can be fixed during this process. Fourth, plants may develop root system to capture nutrients in deeper soil layers during the recovery period. In this synthesis, only studies at two sites reported the root biomass in soil below $50 \mathrm{~cm}$ (Yan et al., 2008; Sun et al., 2009). The results at both sites illustrate that GE leads to an increase of root biomass in $50-80 \mathrm{~cm}$ by $85 \%-159 \%$, which is much higher than that in soil above $50 \mathrm{~cm}(<40 \%)$. These results imply that more $\mathrm{N}$ would be available owing to the development of root systems in deeper soil. In addition, a relatively big increase of soil $\mathrm{C}$ content in soil below $50 \mathrm{~cm}$ is exhibited (Fig. 3b), supporting the hypothesis that root biomass in deeper soil is greatly promoted as a consequence of GE. Notably, the $\mathrm{C}: \mathrm{N}$ ratio at the grazing sites was lower than that at the fenced sites at the late recovery stage (Fig. $7 \mathrm{~b}$ ). This implies that the accretion of $\mathrm{N}$ could not meet the demand of $\mathrm{C}$ increase at this stage. On the other hand, the supply of soil $\mathrm{N}$ is a key factor determining the rate of soil $\mathrm{C}$ change at the middle and late stage (Table 1). This suggests that insufficient $\mathrm{N}$ supply may be a key reason for the diminishing $C$ sequestration capacity in the late stage of GE.

\section{Conclusions}

This synthesis indicates that GE promotes soil C content and vegetation biomass in grasslands in China. In spite of distinct trajectories for soil $\mathrm{C}$ content and vegetation biomass during the process of recovery, all $\mathrm{C}$ pools reach an equilibrium state after ca. 15 years of GE. The rate of change in soil $\mathrm{C}$ is higher at sites with higher precipitation, implying that the national restoration projects for grasslands in China would yield higher benefit of $\mathrm{C}$ sequestration in regions with wetter climate. The increase in soil $\mathrm{C}$ content is accompanied by soil $\mathrm{N}$ content, suggesting that $\mathrm{N}$ may be a key factor sustaining the increase of soil $\mathrm{C}$ content at the early stage of GE. However, insufficient $\mathrm{N}$ supply may be the main reason for the diminishing $\mathrm{C}$ sequestration capacity at the late stage.

\section{Acknowledgements}

This research was jointly funded by the Strategic Priority Research Program of CAS (grant no. XDA05050201), National Natural Science Foundation of China (grant nos' 31570437,
41301043, 31420103917, 31270519), Youth Innovation Promotion Association, CAS (grant no. 2015037), and the funding for talented young scientists of IGSNRR (2013RC203). We thank Miss Xiaoqiong Huang for her considerable assistance in compiling the data. We also thank the reviewers for providing thoughtful and constructive comments on the earlier version of our manuscript.

\section{References}

Akiyama T, Kawamura K (2007) Grassland degradation in China: methods of monitoring, management and restoration. Grassland Science, 53, 1-17.

Deng L, Zhang ZN, Shangguan ZP (2014) Long-term fencing effects on plant diversity and soil properties in China. Soil \& Tillage Research, 137, 7-15.

Derner JD, Boutton TW, Briske DD (2006) Grazing and ecosystem carbon storage in the North American Great Plains. Plant and Soil, 280, 77-90.

Fan JW, Zhong HP, Harris W, Yu GR, Wang SQ, Hu ZM, Yue YZ (2008) Carbon storage in the grasslands of China based on field measurements of above- and belowground biomass. Climatic Change, 86, 375-396.

He NP, Yu Q, Wu L, Wang YS, Han XG (2008) Carbon and nitrogen store and storage potential as affected by land-use in a Leymus chinensis grassland of northern China. Soil Biology \& Biochemistry, 40, 2952-2959.

He NP, Wu L, Wang YS, Han XS (2009) Changes in carbon and nitrogen in soil particle-size fractions along a grassland restoration chronosequence in northern China. Geoderma, 150, 302-308.

Hiernaux P, Bielders C, Valentin C, Bationo A, Ferna'ndez-Rivera S (1999) Effects of livestock grazing on physical and chemical properties of sandy soils in Sahelian rangelands. Journal of Arid Environments, 41, 231-245.

Hu YF, Liu JY, Zhuang DF, Cao HX, Yan HM, Yang FT (2005) Distribution characteristics of 137Cs in wind-eroded soil profile and its use in estimating wind erosion modulus. Chinese Science Bulletin, 50, 1155-1159.

Hungate BA, Dukes JS, Shaw MR, Luo YQ, Field CB (2003) Nitrogen and climate change. Science, 302, 1512-1513.

Jiang GM, Han XG, Wu JG (2006) Restoration and management of the Inner Mongolia grasslands require a sustainable strategy. Ambio, 35, 269-270.

Li DJ, Niu SL, Luo YQ (2012) Global patterns of the dynamics of soil carbon and nitrogen stocks following afforestation: a meta-analysis. New Phytologist, 195, 172-181.

Liang Y, Han GD, Zhou H, Zhao ML, Snyman HA, Shan D, Havstad KA (2009) Grazing intensity on vegetation dynamics of a typical steppe in northeast Inner Mongolia. Rangeland Ecology \& Management, 62, 328-336.

Liu YR, Yang C, Zhu ZM, Liu ML (2003) Soil C and N dynamics during desertification of grassland in Northern China. Chinese Journal of Applied Ecology, 15, 1604 1606. (in Chinese with English abstract).

Luo YQ, Weng ES (2011) Dynamic disequilibrium of the terrestrial carbon cycle under global change. Trends in Ecology \& Evolution, 26, 96-104.

Luo Y, Su B, Currie WS et al. (2004) Progressive nitrogen limitation of ecosystem responses to rising atmospheric carbon dioxide. BioScience, 54, 731-739.

Luyssaert S, Inglima I, Jung $\mathrm{M}$ et al. (2007) $\mathrm{CO}_{2}$ balance of boreal, temperate, and tropical forests derived from a global database. Global Change Biology, 13, 2509 2537.

Mcsherry ME, Ritchie ME (2013) Effects of grazing on grassland soil carbon: a global review. Global Change Biology, 19, 1347-1357.

Mekuria W, Veldkamp E, Halle M, Nyssen J, Muys B, Gebrehiwota K (2007) Effectiveness of exclosures to restore degraded soils as a result of overgrazing in Tigray, Ethiopia. Journal of Arid Environments, 69, 270-284.

Nosetto MD, Jobbagy EG, Paruelo JM (2006) Carbon sequestration in semi-arid rangelands: comparison of Pinus ponderosa plantations and grazing exclusion in NW Patagonia. Journal of Arid Environments, 67, 142-156.

Pei SF, Fu H, Wan CG (2008) Changes in soil properties and vegetation following exclosure and grazing in degraded Alxa desert steppe of Inner Mongolia, China. Agriculture Ecosystems \& Environment, 124, 33-39.

Pineiro G, Paruelo JM, Oesterheld M, Jobbagy EG (2010) Pathways of grazing effects on soil organic carbon and nitrogen. Rangeland Ecology \& Management, 63, 109-119.

Poeplau C, Don A, Vesterdal L, Leifeld J, Wesemael BV, Schumacher J, Gensior A (2011) Temporal dynamics of soil organic carbon after land-use change in the temperate zone - carbon response functions as a model approach. Global Change Biology, 17, 2415-2427.

Qiu LP, Wei XR, Zhang XC, Cheng JM (2013) Ecosystem carbon and nitrogen accumulation after grazing exclusion in semiarid grassland. PLOS ONE, 8, e55433. doi:10.1371/journal.pone.0055433. 
Raich JW, Schlesinger WH (1992) The global carbon-dioxide flux in soil respiration and its relationship to vegetation and climate. Tellus Series B-Chemical and Physical Meteorology, 44, 81-99.

Reeder JD, Schuman GE (2002) Influence of livestock grazing on C sequestration in semi-arid mixed-grass and short-grass rangelands. Environmental Pollution, 116, $457-463$.

Savadogo P, Sawadogo L, Tiveau D (2007) Effects of grazing intensity and prescribed fire on soil physical and hydrological properties and pasture yield in the savanna woodlands of Burkina Faso. Agriculture Ecosystems \& Environment, 118, 80-92.

Shrestha G, Stahl PD (2008) Carbon accumulation and storage in semi-arid sagebrush steppe: effects of long-term grazing exclusion. Agriculture Ecosystems \& Environment, 125, 173-181.

Souter NJ, Milne T (2009) Grazing exclusion as a conservation measure in a South Australian temperate native grassland. Grassland Science, 55, 79-88.

Steffens M, Kolbl A, Totsche KU, Kogel-Knabner I (2008) Grazing effects on soil chemical and physical properties in a semiarid steppe of Inner Mongolia (PR China). Geoderma, 143, 63-72.

Su YZ, Li YL, Cui HY, Zhao WZ (2005) Influences of continuous grazing and livestock exclusion on soil properties in a degraded sandy grassland, Inner Mongolia, northern China. Catena, 59, 267-278.

Sun ZJ, Aan SZ, Duan JJ (2009) Effect of enclosure on vegetation and soil nutrient of Sagebrush desert grassland in Xinjiang. Arid Zone Research, 26, 877-882. (in Chinese with English abstract).

Wang W, Fang JY (2009) Soil respiration and human effects on global grasslands. Global and Planetary Change, 67, 20-28.

Wang C, Wang XB, Liu DW et al. (2014) Aridity threshold in controlling ecosystem nitrogen cycling in arid and semi-arid grasslands. Nature Communications, 5, 4799. doi:10.1038/ncomms5799.
Wienhold BJ, Hendrickson JR, Karn JF (2001) Pasture management influences on soil properties in the Northern Great Plains. Journal of Soil and Water Conservation, 56, 27-31.

Wu GL, Liu ZH, Zhang L, Chen JM, Hu TM (2010) Long-term fencing improved soil properties and soil organic carbon storage in an alpine swamp meadow of western China. Plant and Soil, 332, 331-337.

Xia JY, Niu SL, Wan SQ (2009) Response of ecosystem carbon exchange to warming and nitrogen addition during two hydrologically contrasting growing seasons in a temperate steppe. Global Change Biology, 15, 1544-1556.

Yan YC, Tang HP, Chang RY, Liu L (2008) Study on the difference of vegetation and soil in typical steppe communities under different fenced time. Journal of Arid Land Resources and Environment, 22, 145-151. (in Chinese with English abstract).

Yang YH, Luo YQ, Finzi AC (2011) Carbon and nitrogen dynamics during forest stand development: a global synthesis. New Phytologist, 190, 977-989.

Zhou ZY, Li FR, Chen SK, Zhang HR, Li GD (2011) Dynamics of vegetation and soil carbon and nitrogen accumulation over 26 years under controlled grazing in a desert shrubland. Plant and Soil, 341, 257-268.

\section{Supporting Information}

Additional Supporting Information may be found in the online version of this article:

Table S1. Data and relevant information of sites used in this synthesis. 